\title{
Simultaneous Determination of Different Phenolic Compounds Using Electrochemical Biosensor and Multivariate Calibration
}

\author{
Renata K. Mendes, ${ }^{*}$, Marcos V. C. Dantas, ${ }^{a}$ Alessandra B. Nogueira, ${ }^{a}$ \\ Augusto Etchegaray, ${ }^{a}$ Paulo R. Filgueiras ${ }^{b}$ and Ronei J. Poppi ${ }^{c}$ \\ ${ }^{a}$ Faculdade de Química, Pontifícia Universidade Católica de Campinas, 13012-970 Campinas-SP, Brazil \\ ${ }^{b}$ Departamento de Química, Universidade Federal do Espírito Santo, 29075-910 Vitória-ES, Brazil \\ 'Instituto de Química, Universidade Estadual de Campinas, CP 6154, 13084-862 Campinas-SP, Brazil
}

\begin{abstract}
Phenolic compounds are important environmental contaminants due to their high toxicity and persistence in the environment. The use of enzyme-based electrochemical biosensors is a simple, sensitive and low-cost alternative for the determination of these pollutants in contaminated waters. However, in most cases, it is impossible to detect specific compounds in a mixture of phenols due to signal-overlap, as the instruments operate at very close potentials, given that the system is based on a single enzyme to detect similar structures. In order to overcome this problem, in the present work we have successfully used multivariate calibration with partial least squares (PLS) for the simultaneous determination of hydroquinone and guaiacol by a tyrosinase-based biosensor that was assembled using an enzyme extract from yam. The use of PLS allowed us to work with a large number of voltammograms, leading to a single mathematical model for the simultaneous determination of phenols of similar structure in real samples with concentration values of $\mathrm{mmol} \mathrm{L}^{-1}$.
\end{abstract}

Keywords: biosensor, phenolic compounds, chemometrics, tyrosinase

\section{Introduction}

Phenolic compounds are basic starting materials for many chemical industries, but can also be generated as side products in chemical processes. Besides their interesting properties, these substances can be extremely toxic and persistent in the environment considering both biotic and abiotic degradation. ${ }^{1}$ The toxicity of phenols include cell permeability, cytoplasmic coagulation, skin irritation, gastrointestinal disorders, renal failure, circulatory problems and pulmonary edema. ${ }^{2}$ Given these characteristics, the phenols and their derivatives are grouped within a list of priority pollutants by the United States Enviromental Protecion Agency (USEPA), being ranked at $11^{\text {th }}$ position in the list of 129 very toxic substances. ${ }^{3}$ Studies on the toxicity of these compounds in water matrices have established that levels of phenolic compounds within the range of ppm can effectively induce alterations in the organoleptic properties of natural waters.

A number of articles have been published describing methods that can be used to detect these compounds

*e-mail: renatavalente@puc-campinas.edu.br in environmental matrices, including instrumental analytical techniques and chromatography, ${ }^{4}$ capillary electrophoresis, ${ }^{5}$ mass spectrometry ${ }^{6}$ and molecular absorption spectrophotometry. ${ }^{7}$ However, these techniques are known to be expensive, require sample pre-treatment and are not adequate for in situ analysis. ${ }^{8}$ Therefore the analytical methods used for phenol detection which are rapid and simple have come into preference when compared to the more sophisticated ones.

An alternative refers to the use of biosensors in view of the fast response, high selectivity and sensibility. In addition, novel approaches have made possible the miniaturization of electrodes and they generate lower residues, thus contributing to green chemistry. ${ }^{9}$ These devices use a biological molecule as the recognizing element, mostly enzymes, ${ }^{10,11}$ as they tend to be less expensive than antibodies or DNA fragments, for instance. Considering the use of oxireductases as the recognizing element, the enzyme tyrosinase is widely used since it has excellent selectivity to phenols and it is readily obtained from vegetables like yam. ${ }^{12}$ The use of crude vegetable extracts as a source of enzyme contributes for an abrupt decrease of the device costs. The extraction of tyrosinases 
from crude extracts requires simple procedures, which are quick and efficient. Furthermore, the extract maintains the enzymatic activity for longer time. ${ }^{13}$

One of the most critical steps in the design and assembly of biosensors is enzyme immobilization. If the recognizing element is not effectively attached, it will be drained to solution during analysis, thus reducing signal and sensibility of the constructed device. The use of nanomaterials in the assembly of these detecting devices offer unique characteristics that give faster response, selectivity and sensibility in comparison with planar surfaces. ${ }^{14}$ The very small dimensions of nanomaterials has contributed significantly to a stunning gain of surface area that generates excellent adsorption properties, which has turned these materials the most widely used in recent years as a platform for biomolecule immobilization. ${ }^{15}$ There is a wide variety of metallic nanoparticles, which can be found in the literature, as supports for biosensor construction, including gold, ${ }^{16}$ platinum, ${ }^{17}$ bismuth ${ }^{18}$ and silver ${ }^{19}$ as well as zinc ${ }^{11}$ and manganese oxides. ${ }^{20}$ However, the use of magnetic nanoparticles based on iron oxides has the benefit of producing adsorptive materials that are responsive to magnetic field, which can be re-dispersed if magnetism is removed, thus offering the advantage for magnetic separation. Therefore, the adsorptive material (nanoparticles) can easily be separated from the liquid phase using a small magnet. ${ }^{21}$ Besides that, the $\mathrm{Fe}_{3} \mathrm{O}_{4}$ nanoparticles are biocompatible, low cost, with advantages of superparamagnetic properties and ease of preparation..$^{22}$

Contributing even more to the versatility of biosensor detection devices, the use of multivariate calibration methods allows the user to obtain additional information about the system under study and to collect information for simultaneous determination of similar compounds. ${ }^{23}$ Generalizing, calibration is an operation that, for instance, correlates a signal with an entrance value for a determination system under specific conditions. ${ }^{24}$ Calibration is based on the generation of mathematical models correlating the signal of a certain analytical device with a property of interest of the analyzed samples. If the correct model is selected, quantification of the desired property in unknown samples is possible, thus allowing the simultaneous determination of substances that produce superimposed signals. The univariate calibration correlates a single response (variable) with the property of interest, while within multivariate calibration there is a relation of a group of responses.

Multivariate calibration is one of the most important topics within chemometric studies. Basically, the multivariate calibration can be taken as the development of a mathematical model that correlates dependent variables such as spectra and voltammograms, with one or more independent variables like concentration. After the construction of the model and from the projection in new independent variables it is possible to predict the values of new samples. ${ }^{25}$ Ibáñez et al. ${ }^{26}$ applied chemometric tools, such as artificial neural networks (ANN) to determine three phenolpollutants simultaneously using three different epoxy-graphite composite electrodes, in which two of them were modified with metal catalysts (gold and palladium, respectively) and another without metals, forming an electrode array. The authors obtained success in the simultaneous determination; however, it was necessary to construct three electrodes with distinct compositions. In addition, the use of noble metals made the device more expensive. The biosensor proposed in this work uses enzyme extracted from vegetables as element of recognition, making the apparatus more selective and low cost.

There is a list of mathematical tools used for multivariate calibration, for instance, classical least square (CLS); multiple linear regression (MLR); principal component regression (PCR) and partial least squares (PLS). The most commonly used tool for analytical chemistry is the PLS method. The PLS models multivariate data by developing a regression on a new base (latent variables, $\mathrm{LV}$ ), which is a linear combination of original variables. ${ }^{27}$ The advantages of PLS are simplicity, fast response and generation of excellent results for linear models. In some cases, it is possible to develop the model even in the presence of soft non-linear data. This can be attained by local adjustments or polynomial data. ${ }^{28}$ There are few works in the literature ${ }^{29,30}$ that present the combination of PLS and voltammetric measurements for the determination of more than one electroactive compound, in which measurements produce overlapping signals. In this context, the present work aims to determine simultaneously two similar phenols (hydroquinone and guaiacol) using an electrochemical biosensor based on tyrosinase immobilized on magnetic nanoparticles coupled to multivariate analysis (PLS).

\section{Experimental}

\section{Reagents}

Guaiacol, hydroquinone, dibasic sodium phosphate heptahydrate and monobasic potassium phosphate were acquired from Synth, mineral oil Nujol@ from Mantecorp and graphite powder from Sigma-Aldrich. All solutions were prepared using deionized water $(>18 \mathrm{M} \Omega \mathrm{cm}$, Milli-Q, Millipore). The selected sample was originated from pulp and paper manufacture and was used $48 \mathrm{~h}$ after collection. The $\mathrm{pH}$ was corrected to 7.0, using $\mathrm{NaOH}$ $0.1 \mathrm{~mol} \mathrm{~L}^{-1}$. 


\section{Extraction of crude tyrosinase from yam}

With the aim of using the same starting material, a cropping zone was determined exclusively to cultivate yam (Dioscorea sp.), which was used as a source of enzyme. After washing and draining, $25 \mathrm{~g}$ of vegetable were unpeeled and sliced to be added to a liquidizer containing $100 \mathrm{~mL}$ of $0.1 \mathrm{~mol} \mathrm{~L}^{-1}$ phosphate buffer (pH 7.0). Polyclar Super R was added (2.5 g) as a protecting agent. ${ }^{31}$ Immediately, the extract was filtered using 4 layers of gauze and the filtrate was centrifuged at $1800 \mathrm{rpm}$ for $20 \mathrm{~min}$ at $4{ }^{\circ} \mathrm{C}$. The supernatant was collected and divided in several aliquots that were stored in the fridge at $4{ }^{\circ} \mathrm{C}$ to be used as the source of tyrosinase.

\section{Biosensor construction}

Initially, iron magnetic nanoparticles $\left(\mathrm{Fe}_{3} \mathrm{O}_{4}\right)$ were washed with phosphate buffer $\mathrm{pH} 7.0$ and with the aid of a magnet, the washing solution was withdrawn and the process was repeated twice. ${ }^{21}$ Then, the nanoparticles were added to an Eppendorf $\AA$ flask containing $200 \mu \mathrm{L}$ of the crude yam extract (4567 $\mathrm{U} \mathrm{mL}^{-1}$ ). This system was incubated in the fridge for $30 \mathrm{~min}$ and every $5 \mathrm{~min}$ it was mixed to facilitate the interaction of enzyme with nanoparticles. After incubation the magnetic nanoparticles loaded with tyrosinase were washed with buffer and added to $0.175 \mathrm{~g}$ of powdered graphite and the mixture was treated with a few drops of mineral oil. The obtained paste was then homogenized in a mortar with pestle for $10 \mathrm{~min}$. Although other authors ${ }^{31,32}$ have used a longer homogenizing time (20 min), in this work, the homogenization for 10 min was carried out successfully. Finally, the paste was inserted into a glass tube in a manner to allow it to make contact with a nickel/copper wire, in order to be used as working electrodes. This carbon-paste electrode was polished over vegetal paper to obtain a smooth surface before data collection.

\section{Electrochemical measurements}

Cyclic voltammograms were acquired in $0.1 \mathrm{~mol} \mathrm{~L}^{-1}$ phosphate buffer, pH 7.0, between 200 and $400 \mathrm{mV}$, at $50 \mathrm{mV} \mathrm{s}^{-1}$. Experiments were performed using an electrochemical cell equipped with a Teflon ${ }^{\circledR}$ cap with connecting dumps for the attachment of the working electrode (biosensor), the reference electrode $(\mathrm{Ag} / \mathrm{AgCl})$ and the platinum counter electrode. All measurements were carried out using a micropotentiostat from AUTOLAB (Metrohm) PGSTAT 101.

\section{Multivariate calibration}

In the construction of a calibration model, the original dataset ( $\mathbf{X}$ matrix (voltammograms) and $\mathbf{y}$ vector with the property to be calibrated (the concentration of hydroquinone and guaiacol)) was divided into two distinct groups that were termed as calibration and prediction. The calibration group contained $67 \%$ of the samples selected for the construction of the model and determination of the optimal number of LV to be used. The prediction group was used to verify the predictable capacity of the model for new samples that did not take part in model construction. Therefore, to carry out this study, 30 samples were produced, in which 20 were selected for calibration and 10 were used as prevision. Each sample contained a distinct ratio of concentration of the compounds under study (guaiacol and hydroquinone).

Cyclic voltammograms were constructed for 220 variables and these were mean center before construction of the PLS model. The number of LV of the PLS model was optimized by cross-validation with venetian blind method (5-fold). Confidence intervals were determined according to the ASTM standard E $1655-12^{33}$ and the work of Portela et al. ${ }^{34}$ The software Matlab $7.8^{35}$ was used for data treatment and analysis.

\section{Atomic force microscope (AFM) imaging}

In order to collect images by AFM a suspension of $\mathrm{Fe}_{3} \mathrm{O}_{4}$ magnetic nanoparticles was applied to a silicone surface (20 × $20 \mathrm{~mm},(100), 10 \mathrm{~W} \mathrm{~cm}^{-1}$, Virginia Semiconductor) and dried in the air for $2 \mathrm{~h}$ at $20{ }^{\circ} \mathrm{C}$ and $60 \%$ humidity. Images were acquired with a Thermo Microscope AutoProbe CP-Research. The ultra-low spring constant of the silicon nitride $\left(\mathrm{Si}_{3} \mathrm{~N}_{4}\right)$ tip (ca. $0.03 \mathrm{~N} \mathrm{~m}^{-1}$ ), which in addition has low curvature (ca. $5 \mathrm{~nm}$ radius), and a scan rate of 1 to $4 \mathrm{~Hz}$, allowed the instrument to scan the surface loaded with nanoparticles without any physical damage. ${ }^{11}$

\section{Results and Discussion}

\section{Characterization of enzyme immobilization}

AFM was used to estimate the size and to study the morphology of the nanoparticles before and after the immobilization of tyrosinase. As shown in Figure 1a it is possible to verify that the iron nanoparticles are dispersed over the silicon surface and they tend to be more spherical with an average diameter of $0.131 \pm 0.022 \mu \mathrm{m}(\mathrm{n}=3)$. However, after enzyme adsorption (Figure 1b), the average diameter has increased to $0.227 \pm 0.074 \mu \mathrm{m}(\mathrm{n}=3)$, thus 


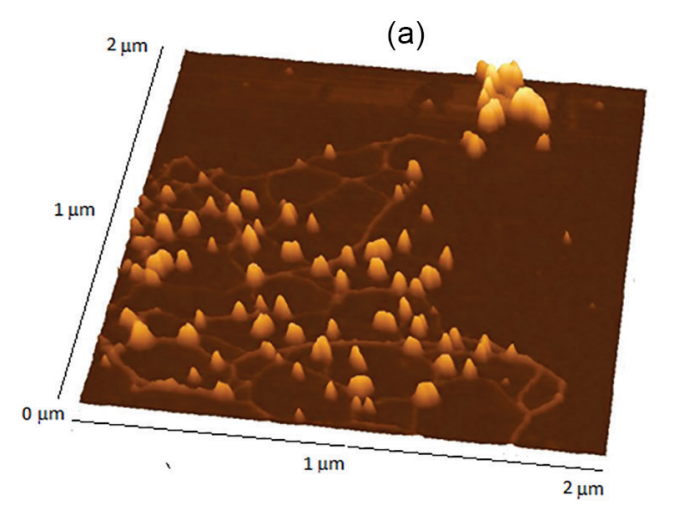

(b)

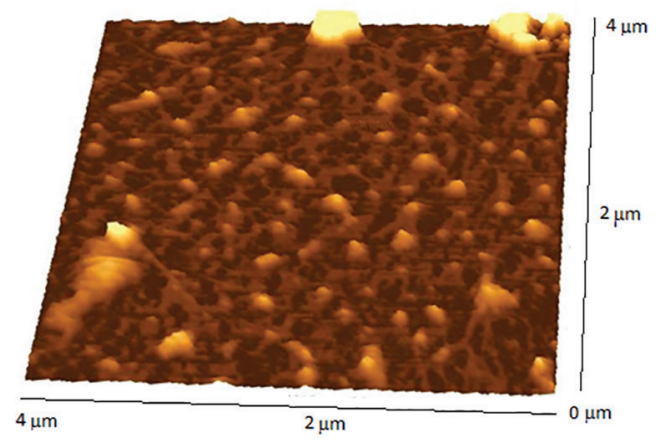

Figure 1. AFM images of $\mathrm{Fe}_{3} \mathrm{O}_{4}$ nanoparticles obtained before (a) and after enzyme immobilization (b).

showing that the process of immobilization was effective even after the washing steps and it is possible to verify that the nanoparticles were uniformly covered with enzyme.

\section{Biosensor response}

In order to test if the use of $\mathrm{Fe}_{3} \mathrm{O}_{4}$ nanoparticles in fact contribute to signal amplification two different devices were prepared. The first biosensor containing only enzymatic extract and graphite powder and another with tyrosinase previously immobilized on the nanoparticles by physical adsorption. An important characteristic in the development of biosensors using $\mathrm{Fe}_{3} \mathrm{O}_{4}$ nanoparticles is their biocompatibility, which makes the environment more appropriate to maintain enzymatic activity. The latter is a crucial problem for these devices, as it affects significantly the stability of measurements. Figure 2 shows the results of this comparative analysis.

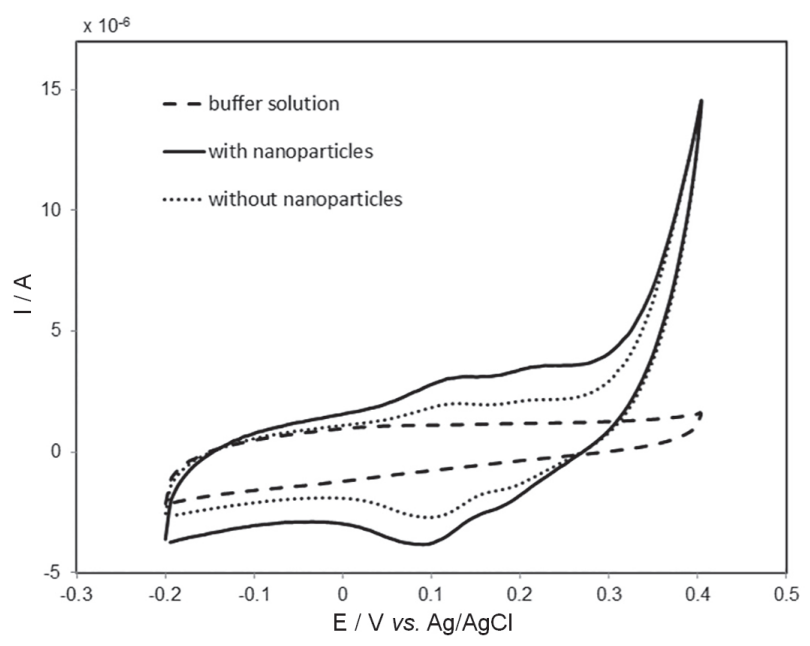

Figure 2. Cyclic voltammograms of biosensor performance with and without $\mathrm{Fe}_{3} \mathrm{O}_{4}$ nanoparticles in $0.1 \mathrm{~mol} \mathrm{~L}^{-1}$ phosphate buffer solution, $\mathrm{pH}$ 7.0, containing $1.0 \mathrm{mmol} \mathrm{L}^{-1}$ of guaiacol. The voltammogram obtained only in buffer solution refers to the biosensor with $\mathrm{Fe}_{3} \mathrm{O}_{4}$ nanoparticles. Scan rate: $50 \mathrm{mV} \mathrm{s}^{-1}$.
Figure 2 shows that the biosensor that was constructed with $\mathrm{Fe}_{3} \mathrm{O}_{4}$ nanoparticles presents a significant enhancement of current values due to a higher ratio of area/volume that is a characteristic of nanomaterials. ${ }^{36}$ The gain in surface area contributes to immobilization of higher amounts of enzyme over the exposed surface, which explains the increase in sensitivity of the apparatus as expected. Besides, nanoparticles can also contribute with the rate of electron transfer ${ }^{37}$ between electrode and active site of the enzyme, making an important feature for electroanalytical determinations. The effect of the nanoparticles was evaluated only for guaiacol, because this phenol produces a much lower electrochemical signal than hydroquinone, showing an increase in the detectability of this contaminant.

Biosensor response in the presence of two phenolic compounds in solution

For this study the biosensor was sequentially immersed in four different solutions: (i) control of buffer only (0.1 mol L-1 phosphate buffer, pH 7.0); (ii) solution containing guaiacol dissolved in the same buffer; (iii) solution that contained hydroquinone in phosphate buffer and (iv) solution containing the two compounds (guaiacol and hydroquinone at equal concentration), also dissolved in phosphate buffer. The results are presented in Figure 3.

The peaks observed in Figure 3 are the result of the electron flux in connection with the redox process occurring for both compounds. The sum of signals is shown in the "mixture profile", which clearly shows an increase in current value due to the presence of superimposed signals originating from hydroquinone and guaiacol oxidation/ reduction processes. As observed in the voltammogram of the mixture, it would be impossible to selectively detect both compounds, using only biosensor response. Therefore, it required a mathematical approach, i.e., chemometric 


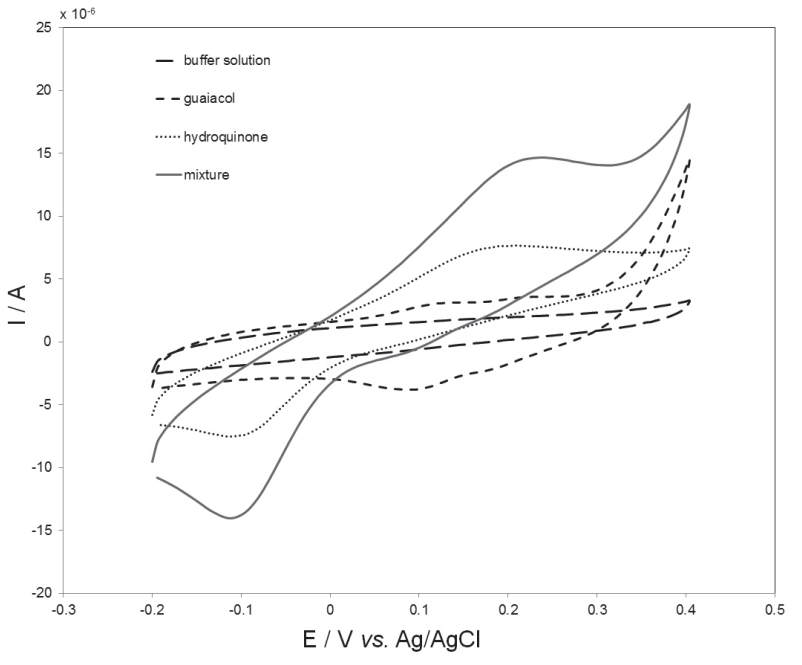

Figure 3. Cyclic voltammograms obtained for the biosensor in $0.1 \mathrm{~mol} \mathrm{~L}^{-1}$, phosphate buffer, $\mathrm{pH} 7.0$, containing: guaiacol $\left(1.0 \mathrm{mmol} \mathrm{L}^{-1}\right)$; hydroquinone $\left(1.0 \mathrm{mmol} \mathrm{L}^{-1}\right)$; a mixture of both phenols at equal concentration. Scan rate was performed at $50 \mathrm{mV} \mathrm{s}^{-1}$.

analysis, in order to identify these compounds separately in the same sample.

\section{Multivariate analysis using PLS}

The concentrations of guaiacol and hydroquinone (properties of interest in the analysis) are highly correlated. There is a linear correlation with concentration for both components in the sample. This can be observed in Figure 4, as the peak current rises when the concentration values of both guaiacol and hydroquinone increase. This linear relationship between the concentrations of the two components and the corresponding voltammograms would be best studied if modeledby multivariate calibration. The chosen method was PLS, since it takes into consideration not only single current peaks (maximum or minimum), but the full cyclic voltammogram obtained during the analysis. Therefore, it is possible to gain more information with the same dataset, considering that the direct relation within the concentrations of guaiacol and hydroquinone with the oxidation peaks would not sufficiently describe the property of interest (Figure S1, Supplementary Information section).

The number of LV of the PLS model was optimized here using the (5-fold) venetian blind method. The four LV described by the PLS model may be related to the oxidized and reduced species of the components guaiacol and hydroquinone. We used the SIMPLE algorithm. In Figure 5 it is observed that the first $\mathrm{LV}$ describes a profile of the voltammogram, while the second presents a peak of reduction in approximately $0.5 \mathrm{~V}$. The loadings of the third and fourth components exhibit an oxidation peak at approximately $-0.5 \mathrm{~V}$.

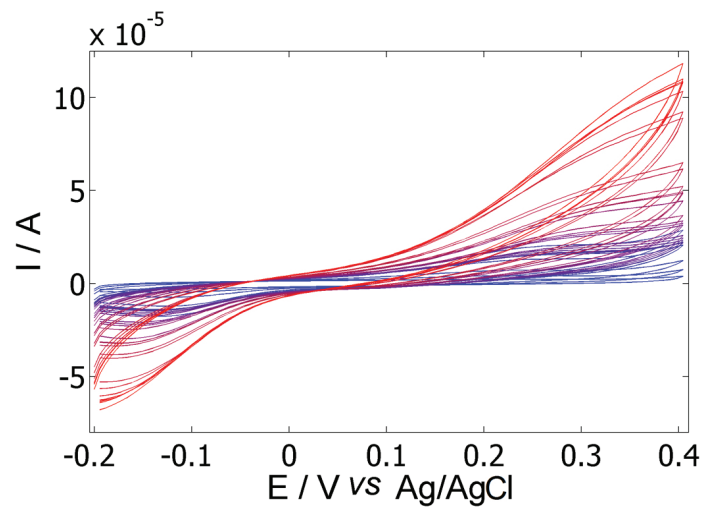

Figure 4. Cyclic voltammograms for the mixture guaiacol/hydroquinone obtained during the analysis of the proposed biosensor in phosphate buffer $\left(0.1 \mathrm{~mol} \mathrm{~L}^{-1}, \mathrm{pH} 7.0\right)$. In blue we see the effect of the addition of low concentrations of both phenols; the red traces correspond to higher concentrations values. The range of concentrations used varied from 1 to $5 \mathrm{mmol} \mathrm{L}^{-1}$ for the lowest and highest values. Scan rate was performed at $50 \mathrm{mV} \mathrm{s}^{-1}$.

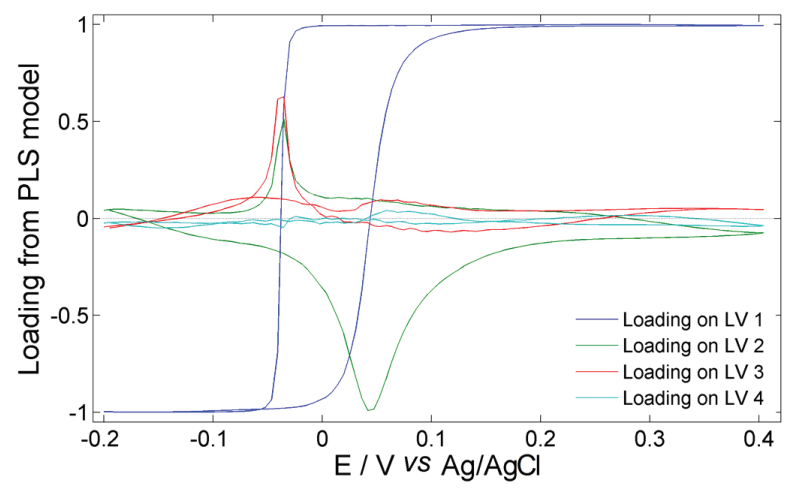

Figure 5. Loading signal profiles from PLS model constructed to estimate the content of guaiacol.

In Figure 6, we observe that the error of cross-validation is reduced up to $4 \mathrm{LV}$. Above this value, no significant variation is observed with increments of LV considering the root mean square error of cross-validation (RMSECV). Therefore, the PLS model was constructed with 4 LV. This $\mathrm{LV}$ number is possibly associated with the chemical species

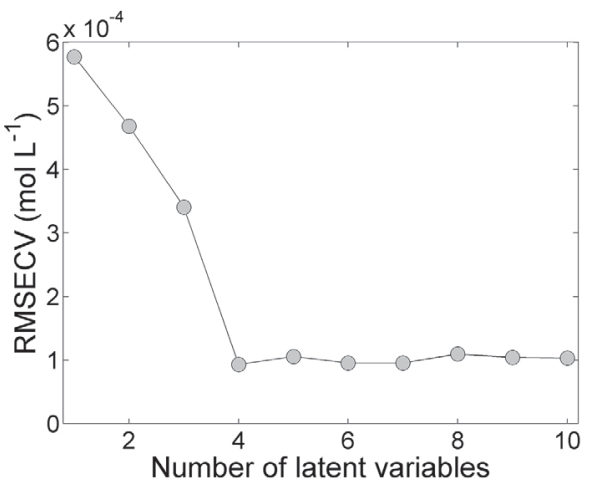

Figure 6. Effect of the number of LV on the error of cross-validation (RMSECV). 
guaiacol and hydroquinone, respectively in their oxidized and reduced forms.

The root mean square errors (RMSE) and of the prediction (RMSEP) of the models used for quantification of guaiacol and hydroquinone are similar, that is, they do not present over adjustments and are below the minimum level of these components in the mixture (Table 1). The good linear relation between the values of reference concentration and predicted by the PLS model with $4 \mathrm{LV}$ can be observed by the high coefficient of determination $\left(\mathrm{R}^{2}\right)$ obtained for the models, with values exceeding 0.99. This can also be observed by the good fit presented by the models on Figures 7 and 8, in which one observes excellent correlation between values of concentration predicted and measured.

Employing the multivariate method, we observed an expressive gain in information in comparison with an univariate method. The univariate method utilizing the same group of samples for the multivariate method has presented RMSEP of $6.70 \times 10^{-4}$ and $3.80 \times 10^{-4} \mathrm{~mol} \mathrm{~L}^{-1}$ for guaiacol and hydroquinone, respectively (Table S1 in the Supplementary Information (SI) section). An $F$-test indicated that there is a significant statistic difference between the accuracy of the univariate and the multivariate models for quantification of guaiacol and hydroquinone at $5 \%$ of significance level. The concentrations of guaiacol and hydroquinone are related to the profile of cyclic voltammograms of the mixture, which explains the development of a calibration model with a higher number of variables, an information that better describes the variation of concentration of the species of interest than an univariate model.

Table1. Merit figures of the PLS model for quantification of the guaiacol and hydroquinone concentrations in phosphate buffer $\left(0.1 \mathrm{~mol} \mathrm{~L}^{-1}, \mathrm{pH} 7.0\right)$

\begin{tabular}{|c|c|c|}
\hline Statistic parameter & Guaiacol & Hydroquinone \\
\hline RMSEC / $\left(\mathrm{mol} \mathrm{L}^{-1}\right)$ & $8.56 \times 10^{-5}$ & $4.83 \times 10^{-5}$ \\
\hline RMSECV / $\left(\mathrm{mol} \mathrm{L}^{-1}\right)$ & $9.30 \times 10^{-5}$ & $5.27 \times 10^{-5}$ \\
\hline RMSEP / $\left(\mathrm{mol} \mathrm{L}^{-1}\right)$ & $11.9 \times 10^{-5}$ & $6.73 \times 10^{-5}$ \\
\hline $\mathrm{R}^{2}$ calibration & 0.9981 & 0.9981 \\
\hline $\mathrm{R}^{2}$ cross-validation & 0.9970 & 0.9970 \\
\hline $\mathrm{R}^{2}$ prediction & 0.9956 & 0.9956 \\
\hline
\end{tabular}

RMSEC: root mean square error of calibration; RMSECV: root mean square error of cross-validation; RMSEP: root mean square error of prediction; $\mathrm{R}^{2}$ : coefficient of determination.

\section{Determination of phenols in real samples}

After construction of the calibration curve, the biosensor was used to quantify guaiacol and hydroquinone in an industrial wastewater. This sample was purposely

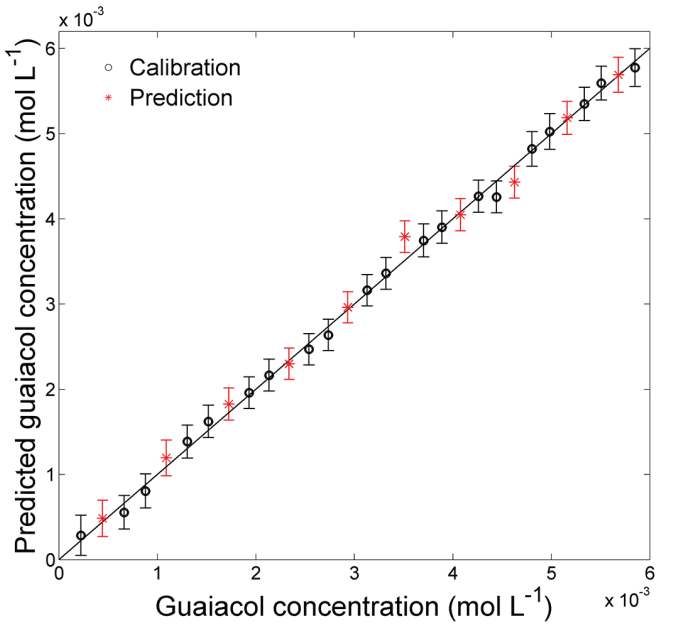

Figure 7. Predicted guaiacol concentration as for the PLS model using $4 \mathrm{LV}$ versus the reference concentration of guaiacol $\left(\mathrm{mol} \mathrm{L}^{-1}\right)$ (Table S2 in the SI section). Error bars in each marker refer to the confidence interval of $95 \%$ in each prediction. The black line represents the ideal linear relation.

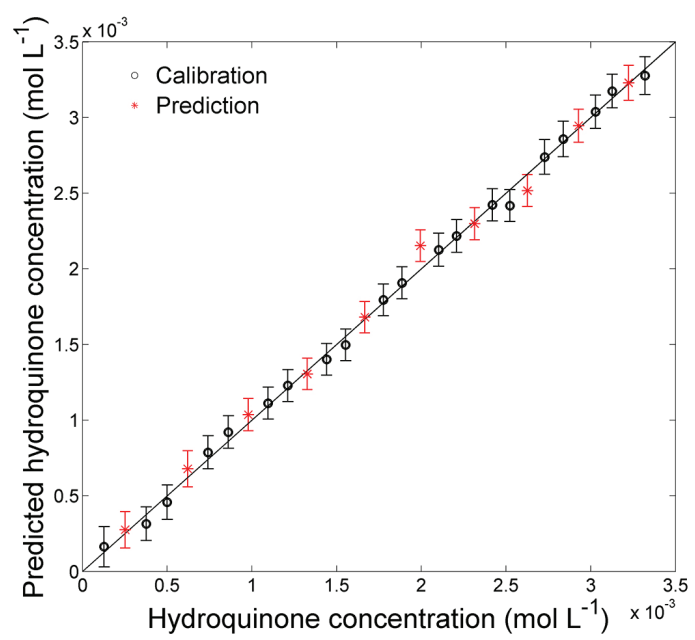

Figure 8. Predicted hydroquinone concentration as for the PLS model using $4 \mathrm{LV}$ versus the reference concentration of hydroquinone $\left(\mathrm{mol} \mathrm{L}^{-1}\right)$ (Table S2 in the SI section). Error bars in each marker refer to the confidence interval of $95 \%$ in each prediction. The black line represents the ideal linear relation.

contaminated with the mixture phenols. Table 2 presents the results obtained.

Observing the values added and the concentrations found, it is possible to verify that the biosensor is able to determine the level of these phenols separately in a mixture contained in a real sample. The relative error obtained is low (1.3 to $4.4 \%$ ), which shows that the biosensor is accurate and selective because the other substances present in the sample did not interfere in the quantification of these contaminants.

\section{Conclusions}

There are few works that describe the use of multivariate calibration applied to electroanalysis. However, the 
Table 2. Simultaneous quantification of the guaiacol and hydroquinone concentrations in industrial wastewater (pH 7.0). Phenol contents determined by the PLS model with 4 latent variables (in parentheses represent the confidence interval with 95\%)

\begin{tabular}{lcccc}
\hline Sample & Guaiacol added / $\left(\mathrm{mol} \mathrm{L}^{-1}\right)$ & Hydroquinone added / $\left(\mathrm{mol} \mathrm{L}^{-1}\right)$ & Guaiacol found / $\left(\mathrm{mol} \mathrm{L}^{-1}\right)$ & Hydroquinone found / $\left(\mathrm{mol} \mathrm{L}^{-1}\right)$ \\
\hline 1 & 0.0075 & 0.0045 & $0.0076 \pm 0.0009$ & $0.0043 \pm 0.0009$ \\
2 & 0.0050 & 0.0030 & $0.0051 \pm 0.0007$ & $0.0029 \pm 0.0004$ \\
\hline
\end{tabular}

successful application of multivariate calibration (PLS) for biosensor analysis of similar samples in a single measurement is a great achievement. Using the appropriate mathematical model developed by the application of partial least squares method it was possible to take advantage of a number of informative parameters from a single voltammogram, allowing the use of a single model to simultaneously determine the concentration of more than one compound with similar chemical structures in industrial wastewater. These characteristics make the device presented a promising alternative for use in the environmental area, besides presenting low cost of construction because it uses vegetal extracts as an enzymatic source.

\section{Supplementary Information}

Supplementary information (curve presenting the relation between the reference values and those predicted by univariate linear regression for the analyzedphenols; results of the univariate linear regression models and guaiacol/hydroquinone contents in the samples used in the calibration and prediction of the PLS model) is available free of charge at http://jbcs.sbq.org.br as PDF file.

\section{Acknowledgments}

The authors would like to acknowledge Fundação de Amparo à Pesquisa do Estado de São Paulo (FAPESP Process No. 2013/20570-6) and the Conselho Nacional de Desenvolvimento Científico e Tecnológico (CNPq) for the financial support. We would also like to acknowledge Prof Dr E. F. de Souza (PUC-Campinas) for the iron magnetic nanoparticles and Prof Dr O. Teschke (IFGW, Unicamp) for the AFM images.

\section{References}

1. Yang, L.; Fan, S.; Deng, G.; Li, Y.; Ran, X.; Zhao, H.; Li, C.-P.; Biosens. Bioelectron. 2015, 68, 617.

2. Karim, N.; Lee, H. J.; Talanta 2013, 116, 991.

3. Bazrafshan, E.; Mostafapour, F. K.; Mansourian, H. J.; Health Scope 2013, 2, 65.

4. Criado-García, L.; Garrido-Delgado, R.; Arce, L.; López, F.; Peón, R.; Valcárcel, M.; Talanta 2015, 144, 944.
5. Wei, W.; Yin, X.-B.; He, X.-W.; J. Chromatogr. A 2008, 1202, 212.

6. Pan, S.-D.; Chen, X.-H.; Shen, H.-Y.; Li, X.-P.; Cai, M.-Q.; Zhao, Y.-G.; Jin, M.-C.; Anal. Chim. Acta 2016, 919, 34.

7. Al-Jadidi, H. S. K.; Hossain, M. A.; Asian Pac. J. Trop. Dis. 2016, 6, 376.

8. Cevik, E.; Senel, M.; Baykal, A.; Abasıyanık, M. F.; Sens. Actuators, B 2012, 173, 396.

9. Apetrei, I. M.; Apetrei, C.; J. Food Eng. 2015, 149, 1.

10. Sekretaryova, A. N.; Volkov, A. V.; Zozoulenko, I. V.; Turner, A. P. F.; Vagin, M. Y.; Eriksson, M.; Anal. Chim. Acta 2016, 907,45 .

11. Mendes, R. K.; Arruda, B. S.; Souza, E. F.; Nogueira, A. B.; Teschke, O.; Bonugli, L. O.; Etchegaray, A.; J. Braz. Chem. Soc. 2017, 28, 1212.

12. Liu, X.; Yan, R.; Zhu, J.; Zhang, J.; Liu, X.; Sens. Actuators, B 2015, 209, 328.

13. Fatibello-Filho, O.; Vieira, I.; Quim. Nova 2002, 25, 455.

14. Zhang, Y.; Wei, Q.; J. Electroanal. Chem. 2016, 781, 401.

15. Ríos, A.; Zougagh, M.; TrAC, Trends Anal. Chem. 2016, 84, 72.

16. Magar, H. S.; Ghica, M. E.; Abbas, M. N.; Brett, C. M. A.; Talanta 2017, 15, 462

17. Borisova, B.; Sánchez, A.; Jiménez-Falcao, S.; Martín, M.; Salazar, P.; Parrado, C.; Pingarrón, J. M.; Villalonga, R.; Sens. Actuators, B 2016, 232, 84.

18. Bindewald, E. H.; Schibelbain, A. F.; Papi, M. A. P.; Neiva, E. G. C.; Zarbin, A. J. G.; Bergamini, M. F.; Marcolino-Junior, L. H.; Mater. Sci. Eng., C 2017, 79, 262.

19. Alessio, P.; Martin, C. S.; Saja, J. A.; Rodriguez-Mendez, M. L.; Sens. Actuators, B 2016, 233, 654.

20. Shoja, Y.; Rafati, A. A.; Ghodsi, J.; Mater. Sci. Eng., C 2017, 76, 637.

21. Mendes, R. K.; Laschi, S.; Stach-Machado, R.; Kubota, L. T.; Marrazza, G.; Sens. Actuators, B 2012, 166-167, 135.

22. Wang, Y.; Sun, Y.; Dai, H.; Ni, P.; Jiang, S.; Lu, W.; Li, Z.; Li, Z.; Sens. Actuators, B 2016, 236, 621 .

23. Rojas, J.; Tachon, A. F.; Chevalier, D.; Noguer, T.; Marty, J. L.; Ghommidh, C.; Sens. Actuators, B 2004, 102, 284.

24. Neto, B. B.; Pimentel, M. F.; Araújo, M. C. U.; Quim. Nova 2002, 25, 856.

25. Valderrama, P.; Braga, J. W. B.; Poppi, R. J.; Quim. Nova 2009, 32,1278

26. Ibáñez, A. B.; Gutés, A.; Baeza, M.; Céspedes, F.; Anal. Lett. 2008, 41, 1419. 
27. de Aguiar, J. G.; Borin, A.; Poppi, R. J.; J. Braz. Chem. Soc. 2010, 21, 436.

28. Centner, V.; Noord, O. E.; Massar, D. L.; Anal. Chim. Acta 1998, 376, 153.

29. Freire, R. S.; Ferreira, M. M. C.; Durán, N.; Kubota, L. T.; Anal. Chim. Acta 2003, 485, 263.

30. Gutés, A.; Ibáñez, A. B.; Céspedes, F.; Alegret, S.; Del Valle, M.; Anal. Bioanal. Chem. 2005, 382, 471.

31. Vieira, I.; Lupetti, K.; Fatibello-Filho, O.; Quim. Nova 2003, $26,39$.

32. Oliveira, I. R. W. Z.; Fernandes, S. C.; Vieira, I. C.; J. Pharm. Biomed. Anal. 2006, 41, 366.
33. ASTM E1655-05(2012), Standard Practices for Infrared Multivariate Quantitative Analysis, ASTM International: West Conshohocken, PA, 2012.

34. Portela, N. A.; Oliveira, E. C. S.; Neto, A. C.; Rodrigues, R. R. T.; Silva, S. R. C.; Castro, E. V. R.; Filgueiras, P. R.; Fuel 2016, 166, 12.

35. MATLAB 7.8; The MathWorks, Inc.: Natick, MA, USA, 2009.

36. Rocha-Santos, T. A. P.; TrAC, Trends Anal. Chem. 2014, 62, 28.

37. Vidotti, M.; Carvalhal, R. F.; Mendes, R. K.; Ferreira, D. C. M.; Kubota, L. T.; J. Braz. Chem. Soc. 2011, 22, 3.

Submitted: June 19, 2017

Published online: September 11, 2017 